\title{
Sir2/Sirt1 Links Acute Inebriation to Presynaptic Changes and the Development of Alcohol Tolerance, Preference, and Reward
}

\author{
[Q Gregory L. Engel, ${ }^{1}$ Sunanda Marella, ${ }^{2}$ Karla R. Kaun, ${ }^{3}$ Julia Wu, ${ }^{2}$ Pratik Adhikari, ${ }^{1}$ Eric C. Kong, ${ }^{2}$ and Fred W. Wolf 1,2 \\ ${ }^{1}$ School of Natural Sciences, University of California, Merced, Merced, California 95343, ${ }^{2}$ Ernest Gallo Clinic and Research Center, University of California \\ San Francisco, Emeryville, California 94608, and ${ }^{3}$ Department of Neuroscience, Brown University, Providence, Rhode Island 02912
}

Acute ethanol inebriation causes neuroadaptive changes in behavior that favor increased intake. Ethanol-induced alterations in gene expression, through epigenetic and other means, are likely to change cellular and neural circuit function. Ethanol markedly changes histone acetylation, and the sirtuin Sir2/SIRT1 that deacetylates histones and transcription factors is essential for the rewarding effects of long-term drug use. The molecular transformations leading from short-term to long-term ethanol responses mostly remain to be discovered. We find that Sir2 in the mushroom bodies of the fruit fly Drosophila promotes short-term ethanol-induced behavioral plasticity by allowing changes in the expression of presynaptic molecules. Acute inebriation strongly reduces Sir 2 levels and increases histone $\mathrm{H} 3$ acetylation in the brain. Flies lacking Sir2 globally, in the adult nervous system, or specifically in the mushroom body $\alpha / \beta$-lobes show reduced ethanol sensitivity and tolerance. Sir2-dependent ethanol reward is also localized to the mushroom bodies, and Sir2 mutants prefer ethanol even without a priming ethanol pre-exposure. Transcriptomic analysis reveals that specific presynaptic molecules, including the synaptic vesicle pool regulator Synapsin, depend on Sir2 to be regulated by ethanol. Synapsin is required for ethanol sensitivity and tolerance. We propose that the regulation of Sir2/SIRT1 by acute inebriation forms part of a transcriptional program in mushroom body neurons to alter presynaptic properties and neural responses to favor the development of ethanol tolerance, preference, and reward.

Key words: addiction; behavior; Drosophila; ethanol; transcriptional regulation

Significance Statement

We identify a mechanism by which acute ethanol inebriation leads to changes in nervous system function that may be an important basis for increasing ethanol intake and addiction liability. The findings are significant because they identify ethanol-driven transcriptional events that target presynaptic properties and direct behavioral plasticity. They also demonstrate that multiple forms of ethanol behavioral plasticity that are relevant to alcoholism are initiated by a shared mechanism. Finally, they link these events to the Drosophila brain region that associates context with innate approach and avoidance responses to code for reward and other higher-order behavior, similar in aspects to the role of the vertebrate mesolimbic system.

\section{Introduction}

Alcoholism is the most prevalent form of drug addiction, and it has broad socioeconomic impacts, including lost productivity,

Received Feb. 11, 2016; revised March 17, 2016; accepted March 23, 2016.

Author contributions: G.L.E. and F.W.W. designed research; G.L.E., S.M., K.R.K., J.W., P.A., E.C.K., and F.W.W. performed research; G.L.E., S.M., K.R.K., J.W., P.A., E.C.K., and F.W.W. analyzed data; G.L.E. and F.W.W. wrote the paper.

This work was supported by a grant from the National Institute on Alcohol Abuse and Alcoholism. We thank Shamsideen 0jelade, Adrian Rothenfluh, and Masashi Kitazawa for advice.

The authors declare no competing financial interests.

Correspondence should be addressed to Fred W. Wolf, School of Natural Sciences, University of California, Merced, 5200 North Lake Road, Merced, CA 95343. E-mail: fwolf@ucmerced.edu.

DOI:10.1523/JNEUROSCI.0499-16.2016

Copyright $\odot 2016$ the authors $\quad 0270-6474 / 16 / 365241-11 \$ 15.00 / 0$ interpersonal discord, and high medical costs. The pharmacological effects of ethanol lead to long-term changes in neurophysiology and behavior. Some of these changes are maladaptive and underlie the shifts in behavior that are characteristic of alcohol abuse and dependence. However, the molecular mechanisms underlying these maladaptive changes are not well understood. Recently, gene expression regulation in the nervous system, facilitated by changes in chromatin conformation, have been shown to contribute to the development of ethanol tolerance, preference, and reinstatement (Mahadev and Vemuri, 1998; Kerns et al., 2005). Covalent modification of core histones is a major mechanism for dynamically regulating chromatin conformation and gene expression. Ethanol and other drugs of abuse cause marked changes in histone acetylation and methylation 
(Maze and Nestler, 2011). Specifically, short-term ethanol exposure increases the acetylation of histones $\mathrm{H} 3$ and $\mathrm{H} 4$ in the amygdala, and induces histone modifications in other brain regions (Pandey et al., 2008; Finegersh and Homanics, 2014).

Ethanol exerts some of its long-term effects through altering the activity of the enzymes that modify histones. This includes the protein lysine deacetylase/histone deacetylases (HDACs) that remove acetyl groups to generally decrease transcription from nearby genes. Short-term ethanol exposure in rats decreases HDAC activity, and withdrawal from long-term ethanol use increases HDAC activity, changes that are predicted to increase and decrease gene transcription, respectively (Pandey et al., 2008). Further, pharmacological reduction of HDAC activity in ethanol withdrawal reduces anxiety-like behavior and tolerance to the anxiolytic effects of ethanol (Sakharkar et al., 2012). Similarly, long-term cocaine use increases HDAC activity, and pharmacological manipulation of the sirtuin HDAC Sirtl alters cocaine reward (Renthal et al., 2009). These data suggest that changes in chromatin structure through the regulation of HDACs and other chromatin-modifying enzymes contribute to drug-induced behavioral plasticity, possibly through transcriptional regulatory mechanisms.

Drosophila become inebriated by ethanol produced by fermenting fruit, which is a major source of nutrition, a site for reproduction, and also a source of protection from predators (Dudley, 2000; Kacsoh et al., 2013). Drosophila develop a preference for ethanol intake and tolerance to its inebriating and sedating effects after repeated or prolonged exposure (Scholz et al., 2000; Devineni and Heberlein, 2009). Furthermore, flies find ethanol rewarding, and they show signs of withdrawal after a period of abstinence (Kaun et al., 2011; Shohat-Ophir et al., 2012; Ghezzi et al., 2014). Molecularly, ethanol broadly alters gene expression and also histone modifications in the Drosophila nervous system, including acetylation of histones $\mathrm{H} 3$ and $\mathrm{H} 4$ at specific sites across the genome (Morozova et al., 2006; Urizar et al., 2007; Kong et al., 2010; Ghezzi et al., 2013). The expression of RNA for the Drosophila Sirt1 homolog Sir2 is markedly decreased following short-term exposure to ethanol, and both locomotor and postural control responses to ethanol are affected in flies with decreased Sir2 expression levels (Morozova et al., 2006; Kong et al., 2010). It remains unclear, however, how short-term ethanol exposure causes changes in gene expression and what characteristics of the nervous system are affected. This is an important question to answer because gene expression can lead to lasting changes in nervous system function that are plausibly the basis for increased addiction liability. Here, we use Drosophila to define the role of Sir2 in ethanol-induced behavioral plasticity, and show that ethanol works through Sir2 to change the expression of key presynaptic molecules.

\section{Materials and Methods}

Drosophila genetics and culturing conditions. All strains were outcrossed for at least five generations to the Berlin genetic background carrying the $w^{1118}$ genetic marker mutation. The genetic background strain was used as an experimental control, indicated as "control" in the figures. Flies were cultured on standard cornmeal/molasses/yeast medium at $25^{\circ} \mathrm{C}$ and $70 \%$ relative humidity with an $\sim 16 / 8 \mathrm{~h}$ light/dark schedule, unless otherwise indicated. Strains used in this study include Sir2 $2^{2 A-7-11}$ (catalog \#8838, Bloomington Drosophila Stock Center [BDSC]), UAS-UASSir2.IR 32481 (catalog \#32481, BDSC), elav(c155)-GAL4 (catalog \#458, BDSC), tub-GAL80 $0^{\text {ts }}$ (catalog \#7019, BDSC), 17d-GAL4 (catalog \#51631, BDSC), UAS-Sir2 (a gift from Alexei Tulin, Fox Chase Cancer Center, Philadelphia, PA), MB-GAL80 (a gift from Scott Waddell, University of Oxford, Oxford, UK; Krashes et al., 2007), UAS-TeTx (a gift from Sean
Sweeney, University of York, York, UK), UAS-Sir2.IR 105502 (catalog \#105502, Vienna Drosophila RNAi Center), Sir2 ${ }^{N P 1145}$ (catalog \#112534, Kyoto Drosophila Genetics Resource Center), and $\operatorname{Syn}^{97}$ (a gift from Giovanni Bosco, Dartmouth College, Hanover, NH).

Ethanol tolerance. Crosses were allowed to lay eggs for $2 \mathrm{~d}$, and groups of $\sim 202$ - to 4-d-old adult male progeny were collected into standard food vials without yeast. These flies were allowed to recover from $\mathrm{CO}_{2}$ anesthesia for $2 \mathrm{~d}$ and were then tested behaviorally.

Behavioral tests were conducted in the booz-o-mat, as previously described (Wolf et al., 2002). Each strain was tested on at least 2 separate days, to control for day-to-day variation. $n$ indicates the total number of groups tested. Flies were allowed to acclimate to the testing chamber for 7-9 min in a stream of humidified air and were then switched to a stream of ethanol vapor (85/65 ethanol vapor/air). At 6 min intervals, the number of flies unable to right themselves was counted. Following a $4 \mathrm{~h}$ interexposure interval, flies were given a second identical exposure. Sedation sensitivity was measured as the time for $50 \%$ of the flies to become sedated during the first exposure (ST50), except where otherwise indicated. Sedation tolerance was measured as the difference between the time to $50 \%$ sedation in the first and second exposures.

Ethanol preference. The capillary feeding assay (CAFE) was used to determine ethanol preference, as previously described (Ja et al., 2007; Devineni and Heberlein, 2009). Groups of eight adult males were collected 3-4 d after eclosion and were allowed to recover for $1 \mathrm{~d}$. They were then exposed to either 85/65 ethanol vapor/air mixture or humidified with air alone for $20 \mathrm{~min}$. After $16 \mathrm{~h}$ of recovery, flies were placed into the CAFE chamber, which consists of empty Drosophila culture vials with capillary tubes containing liquid food, with or without $15 \%$ ethanol, embedded in the vial plug. The preference index was measured as the volume of food consumed over 1 night from the ethanol capillaries minus that consumed from the no-ethanol capillaries over the total volume consumed, corrected for evaporation by measuring the volume lost in tubes with no flies. Bitter taste avoidance was measured by presenting flies with a choice of $1.25 \%$ agarose containing either $50 \mathrm{~mm}$ sucrose $(\mathrm{S})$ or $100 \mathrm{~mm}$ sucrose and $1 \mathrm{~mm}$ quinine (SQ). Approximately 20 male flies were food deprived on water for $14 \mathrm{~h}$, placed in a $40 \times 90 \times 10 \mathrm{~mm}$ clear acrylic arena, and $150 \mu \mathrm{l}$ of $\mathrm{S}$ and SQ dots were then placed in apposition at the center of the arena. The number of flies on each dot was counted at 120 min. Avoidance was calculated as $(\mathrm{SQ}-\mathrm{S}) /(\mathrm{SQ}+\mathrm{S})$, such that complete avoidance of bitter taste gives a value of -1 .

Ethanol reward. The conditioned olfactory preference assay was performed as previously described (Kaun et al., 2011). Groups of 30 male flies were trained to associate an odor with ethanol in three $10 \mathrm{~min}$ repetitions of odor/ethanol pairing. Memory was tested $24 \mathrm{~h}$ later in a Y maze with ethanol-paired and unpaired odors streaming from opposite arms. A preference index was calculated as follows: (number of flies selecting paired odor - number of flies selecting unpaired odor)/total number of flies.

Ethanol absorption and metabolism. Flies were frozen in liquid nitrogen and homogenized in $50 \mathrm{~mm}$ Tris- $\mathrm{HCl}, \mathrm{pH}$ 7.5. Ethanol concentrations were measured in fly homogenates using the Ethanol Assay Kit from Diagnostic Chemicals Ltd. (catalog \#229-29). To calculate the ethanol concentration in flies, the volume of one fly was estimated to be $1 \mu \mathrm{l}$ (Moore et al., 1998).

Western blot. Protein Western blot analysis was performed using standard methods. Whole male fly heads were lysed in RIPA buffer (catalog \#20-188, Millipore); and protein was run on polyacrylamide gels, transferred to PVDF membranes, and probed with antibodies, including the following: rabbit $\alpha$-histone H3 (Active Motif), rabbit $\alpha$-Histone H3 K9 acetylated (Active Motif), rabbit $\alpha$-Sir2 818 (a gift from James Kadonaga, University of California, San Diego, La Jolla, CA), mouse $\alpha$-tubulin (catalog \#T6074, Sigma-Aldrich), mouse $\alpha$-SynORF1 (catalog \#3C11, Developmental Studies Hybridoma Bank), and rabbit $\alpha$-Brp-D2 (a gift from Stephan Sigrist, Free University of Berlin, Berlin, Germany). Blots were secondarily stained with $\alpha$-rabbit HRP (catalog \#NA934V, GE Healthcare Life Sciences) and imaged using the enhanced chemiluminescence method (Mruk and Cheng, 2011), or secondarily stained with goat $\alpha$-Rabbit IRDye $800 \mathrm{CW}$ and goat $\alpha$-Mouse IRDye 680RD (LI-COR) and imaged on a LI-COR Odyssey infrared scanner. 
A

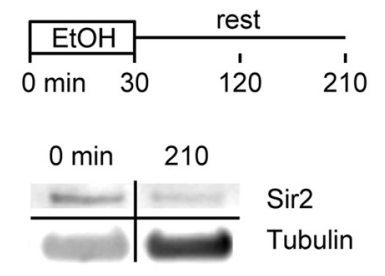

B

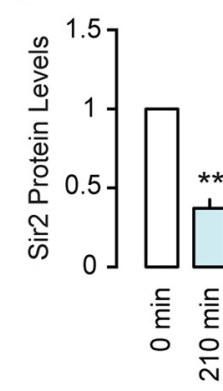

C

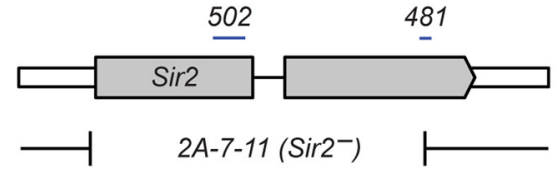

D

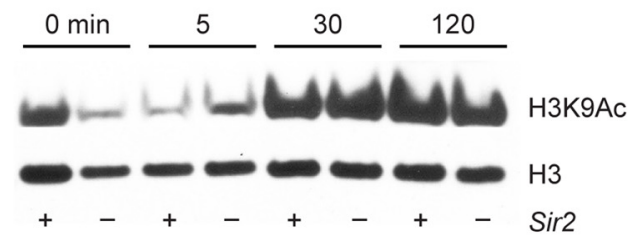

E

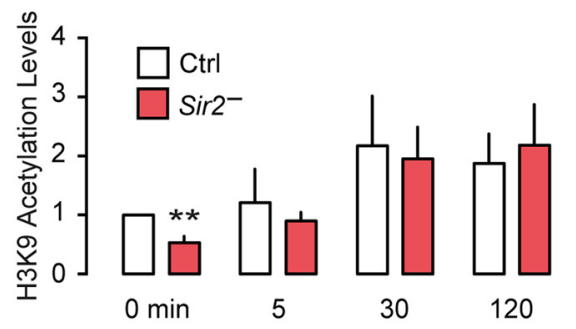

$\mathbf{F}$

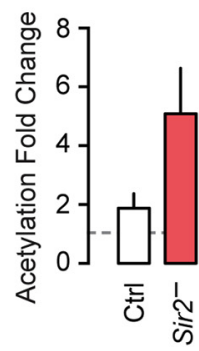

Figure 1. Levels of Sir2 and histone acetylation in fly heads following short-term exposure to ethanol. $\boldsymbol{A}$, Schematic diagram of experimental procedure, and Western blot detecting Sir2 and tubulin proteins (bands rearranged from a single blot). B, Quantification of Sir2 expression normalized to tubulin, relative to unexposed flies $(n=3)$. $\boldsymbol{C}$, Schematic diagram of Sir2 coding region (gray) depicting boundaries of the 2A-7-11 deletion (Sir2- ) and regions used to generate the 502 and 481 RNAi lines. D, Western blot of control (+) and Sir2 ${ }^{-}(-)$heads for acetylated and total H3K9 for the indicated time points during/after ethanol exposure. $\boldsymbol{E}$, Quantification of $\boldsymbol{D}$ showing H3K9Ac levels normalized to total H3, relative to untreated controls $(n=5)$. $\boldsymbol{F}$, Total fold change in $\mathrm{H} 3 \mathrm{~K} 9$ acetylation in control and Sir2 ${ }^{-}$flies between unexposed and ethanol-exposed flies $(n=5)$. Error bars indicate the SE. ${ }^{* *} p<0.01$.

Immunohistochemistry. Immunohistochemistry was performed based upon standard protocols (Wu and Luo, 2006). Adult brains expressing CD2-mCherry were dissected and stained using rabbit $\alpha$-dsRed (catalog \#632496, Clontech), mouse $\alpha$-Brp (catalog \#nc82, Developmental Studies Hybridoma Bank), goat $\alpha$-rabbit 594 (ThermoFisher Scientific), and goat $\alpha$-mouse 488 (ThermoFisher Scientific). Imaging was performed using a Nikon Eclipse Ti C1 Confocal System, and $z$-stacks were compressed using FIJI, and corrected for sample orientation and brightness/ contrast with Adobe Photoshop.

RNA measurement. Groups of 600 male flies were exposed to an 85/65 ethanol vapor/air mixture or a matched flow of humidified air alone for $30 \mathrm{~min}$ and allowed to recover for $3.5 \mathrm{~h}$. Flies were then frozen in liquid nitrogen, and heads were collected. Head RNA was purified using TRIzol reagent (Invitrogen). Poly-A pulldown and cDNA library generation were performed using the manufacturer protocols with a TruSeq Prep Kit (Illumina), then sequenced to a depth of 25 million paired-end reads (Expression Analysis, Inc). Data were analyzed using Galaxy main (https://usegalaxy.org) using the Tuxedo suite of tools (Bowtie, Tophat, and Cufflinks) to align reads to release five of the Drosophila melanogaster annotated genome (Giardine et al., 2005; Blankenberg et al., 2010; Goecks et al., 2010; Trapnell et al., 2012). The resulting gene expression data were filtered for genes with known functions in the nervous system that showed a onefold or higher change in expression between groups and had a minimum expression of 0.1 fragment per kilobase per million. Genes meeting these criteria were further compared with those enriched in the mushroom body (MB; Henry et al., 2012). The putative effector genes identified in this way were further assessed by quantitative PCR (qPCR) across multiple biological and technical replicates.

Statistics. All statistical tests were performed using GraphPad Prism software. Tests used include unpaired $t$ test, one sample $t$ test, and oneway ANOVA with Tukey's post hoc test. All tests performed were two tailed. Significance indicators on the figures indicate the results of $t$ tests or Tukey's tests. Error bars represent the SEM.

\section{Results}

Sir2 is downregulated by acute ethanol exposure

Strongly reduced Sir2 transcript levels soon after acute ethanol exposure led us to ask whether Sir2 regulation initiates an effector program to alter gene expression and behavior (Kong et al., 2010). First, we asked whether Sir2 protein and one of the targets of Sir2 deacetylase activity are affected by acute ethanol exposure. Western blot analysis demonstrated that Sir2 protein is also strongly decreased (unpaired $t$ test, $t_{(4)}=6.82, p=0.0024$; Fig. $1 A, B)$. A dramatic ethanol-induced increase in acetylation of histone $\mathrm{H} 3$ at lysine 9 (H3K9ac), a Sir2 target for deacetylation, in whole head extracts persisted for at least $90 \mathrm{~min}$ after ethanol exposure had ended (Fig. 1D-F). In Sir2 mutant flies (Sir2 ${ }^{-}$) that carry a deletion of the Sir2 gene (Fig. $1 C$ ), we observed an almost doubled increase in $\mathrm{H} 3 \mathrm{~K} 9 \mathrm{ac}$ by ethanol that did not reach statistical significance (unpaired $t$ test, $t_{(8)}=1.98, p=0.0828$; Fig. $1 D-F)$. Maximum levels of H3K9ac did not appear different across genotypes. However, untreated Sir $2^{-}$flies had decreased levels of H3K9ac (one-sample $t$ test, $t_{(4)}=5.18, p=0.0035$; Fig. $1 E)$, suggesting either the existence of compensatory epigenetic mechanisms in the absence of Sir2 HDAC activity or a complexity in the actions of Sir 2 on histones. These data indicated that ethanol causes marked changes in histone acetylation that depends, in part, on the regulation of the HDAC Sir2 by ethanol in flies.

\section{Sir2 acts in the brain to promote ethanol tolerance}

Since ethanol treatment increases protein acetylation, and this is dependent on Sir2, we hypothesized that changes in protein acetylation by Sir 2 contributes to the behavioral responses of flies to ethanol. We measured ethanol sedation sensitivity and the rapid functional tolerance that develops soon after the ethanol accumulated during the first exposure has been metabolized. Naive Sir $2^{-}$flies were strikingly less sensitive to the sedating effects of acute ethanol exposure, taking nearly twice as long to reach $50 \%$ sedation (unpaired $t$ test, $t_{(10)}=23.83, p=0.0001$; Fig. $2 A-C$ ). Sir $2^{-}$flies also showed a marked decrease in sedation tolerance (unpaired $t$ test, $t_{(10)}=5.08, p=0.0005$; Fig. $2 D$ ). These strong behavioral effects were not due to alterations in either ethanol absorption or metabolism (Fig. 2E). Therefore, Sir2 is required to 

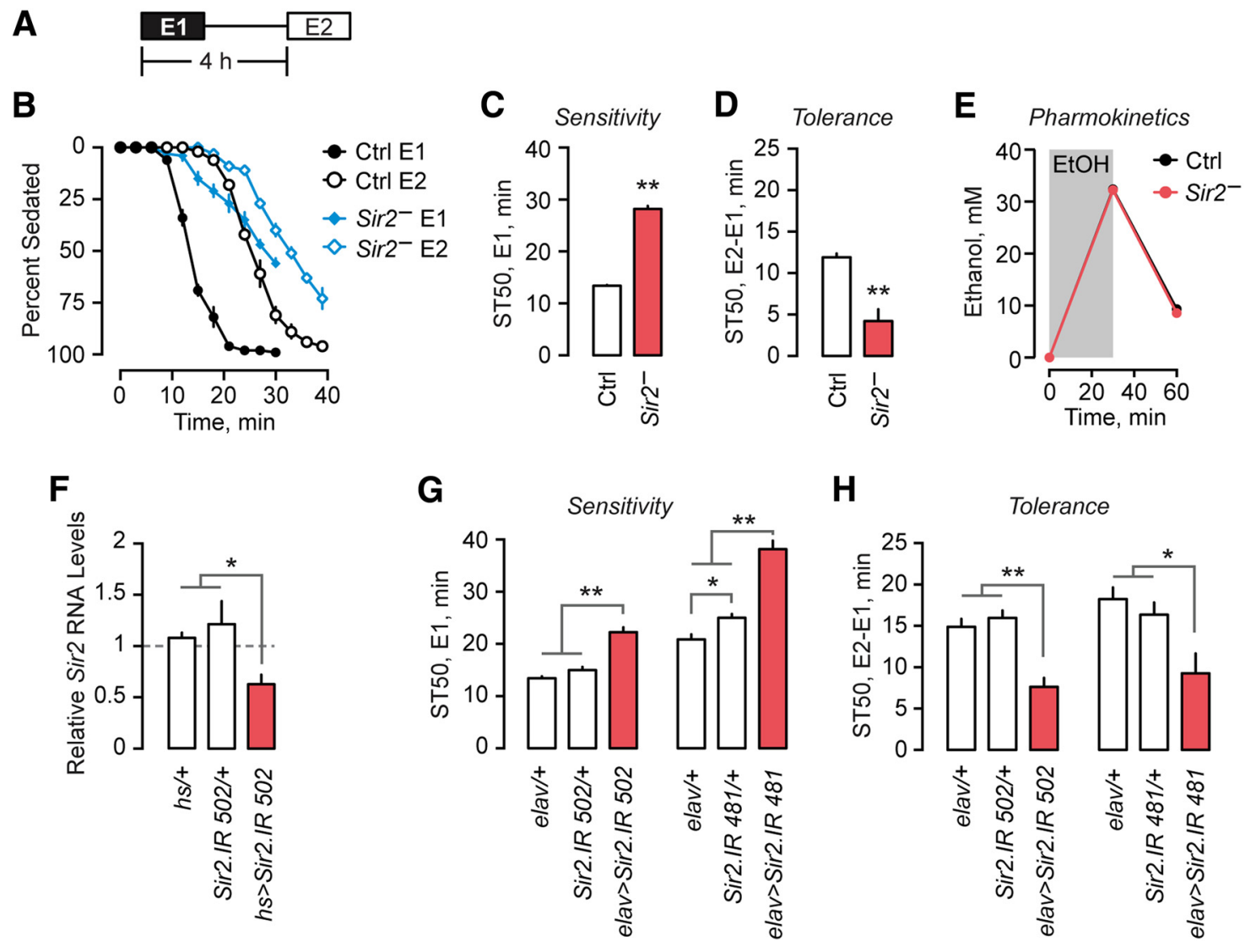

Figure 2. Ethanol sedation sensitivity and tolerance in flies with reduced Sir2 expression. $\boldsymbol{A}$, Exposure scheme for measuring ethanol sedation sensitivity (E1) and tolerance (E2-E1). $\boldsymbol{B}$, Time course of sedation for E1 (closed symbols) and E2 (open symbols) in control (black) and Sir2 ${ }^{-}$(blue) flies $(n=6)$. C, Sedation sensitivity (time to $50 \%$ sedation e1) in Sir2 ${ }^{-}$and control flies ( $n=6$ ). $\boldsymbol{D}$, Sedation tolerance (time to $50 \%$ sedation e2-e1) in Sir2 ${ }^{-}$and control flies $(n=6)$. $\boldsymbol{E}$, Ethanol absorption and metabolism in Sir ${ }^{-}$and control flies. $\boldsymbol{F}$, Sir2 gene expression following RNAi-mediated knockdown using the 502 RNAi line, relative to control flies $(n=3) . \mathbf{G}, \boldsymbol{H}$, Sedation sensitivity $(\boldsymbol{G})$ and sedation tolerance $(\boldsymbol{H})$ in flies expressing Sir2 RNAi transgenes in the nervous system ( $n=9)$. Error bars indicate the SE. ${ }^{*} p<0.05,{ }^{* *} p<0.01$.

promote ethanol sensitivity and facilitate the development of ethanol tolerance.

To determine the tissues where Sir2 is required for ethanol behaviors, we used the GAL4/UAS transgenic system to express Sir2 inverted repeat (Sir2.IR) dsRNA to generate Sir2 RNAi. We determined first that ubiquitous expression of Sir2.IR driven by a heat shock-inducible GAL4 $(h s)$ decreased Sir2 RNA abundance (one-way ANOVA, $F_{(2,12)}=8.68, p=$ 0.0047; Fig. 2F). Decreasing Sir2 in all neurons using the elavGAL4 driver (elav) reduced both sedation sensitivity (one-way ANOVA, $F_{(2,34)}=17.09, p<0.0001$; Fig. $\left.2 G\right)$ and sedation tolerance (one-way ANOVA, $F_{(2,34)}=66.70, p<0.0001$; Fig. $2 H)$. To test for off-target effects, we decreased Sir2 in neurons using a UAS-RNAi that targeted a different region of Sir2 (Sir2.IR 481) and showed that it decreased sedation sensitivity (one-way ANOVA, $F_{(2,36)}=59.07, p<0.0001$; Fig. $2 G$ ) and sedation tolerance (one-way ANOVA, $F_{(2,36)}=6.61, p=$ 0.0036; Fig. 2H). Sir2.IR 481 also decreased Sir2 RNA abundance (one-way ANOVA, $F_{(2,6)}=10.56, p=0.0108$; data not shown). The expression of Sir2.IR in other tissues, including glia and the fat body adipose tissue, did not change ethanol sedation sensitivity or tolerance (data not shown). These results demonstrate that Sir2 is required in neurons to promote ethanol sensitivity and tolerance.

To determine whether the expression of Sir2 in the nervous system was sufficient to allow normal ethanol sensitivity and tolerance, and thus could account for the role of Sir2 in etha- nol behaviors, we performed a genetic rescue experiment, expressing Sir2 in all neurons of flies otherwise lacking functional Sir2 using a UAS-Sir2 transgene. The expression of Sir2 solely in neurons did not rescue the decreased ethanol sedation sensitivity of $\mathrm{Sir}^{-}$mutants (one-way ANOVA, $F_{(3,26)}=0.78$, not significant; Fig. $3 A$ ). However, it did rescue the decreased sedation tolerance phenotype of Sir2 ${ }^{-}$mutants (one-way ANOVA, $F_{(3,26)}=10.32, p<0.0001$; Fig. $3 B$ ). Importantly, these results indicate that the decreased sedation sensitivity and decreased sedation tolerance Sir $2^{-}$phenotypes can be separated: Sir2-dependent tolerance is not due solely to alterations in ethanol sensitivity. The role of Sir2 in ethanol sensitivity may also require its activity in non-neuronal tissues. Alternatively, our genetic rescue scheme may reinstate Sir2 in either an inappropriate expression pattern or level in neurons for the role of Sir2 in sensitivity. However, Sir2 is both necessary and sufficient in the nervous system for the development of ethanol tolerance.

\section{Sir2 is required in adults for ethanol tolerance}

Neuronal Sir2 may contribute to nervous system development, maintenance, physiological function, or a combination thereof to affect ethanol behavioral responses. We performed two complementary experiments to decrease Sir2 function during specific periods of the fly lifespan. First, nicotinamide is a potent endproduct inhibitor of Sir2 deacetylase activity that is active against Sir2 in vivo (Das et al., 2009). Treatment of adult flies with nico- 


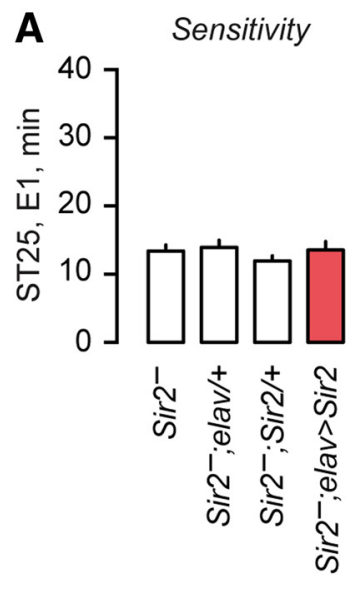

E

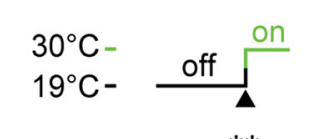

Sensitivity
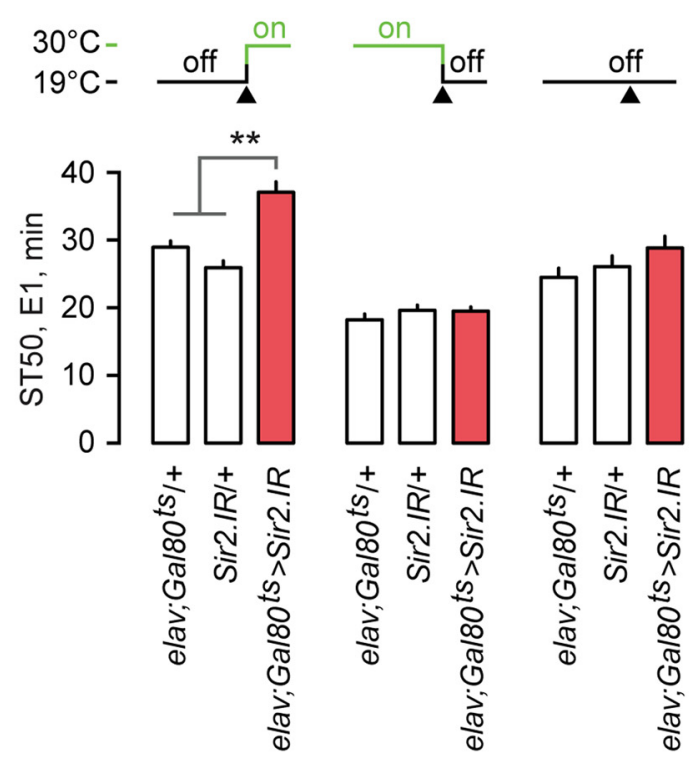

B

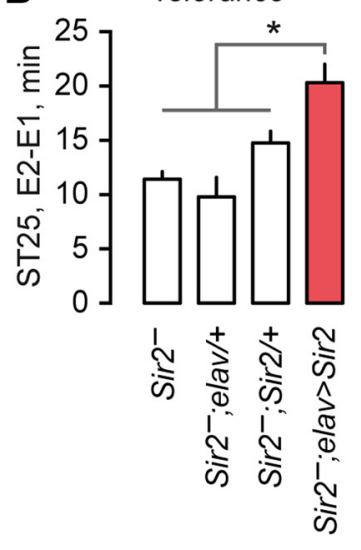

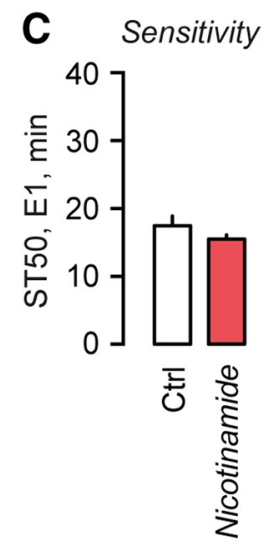

D Tolerance

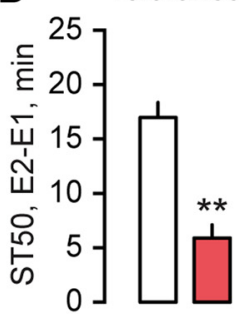

동
$\mathbf{F}$
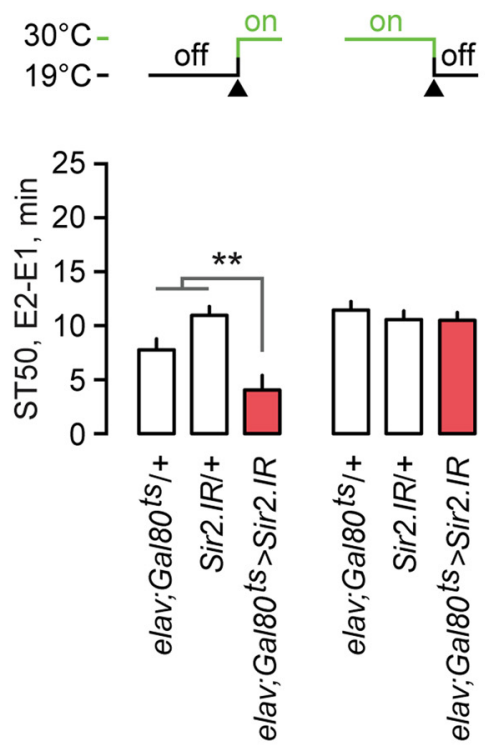

Tolerance
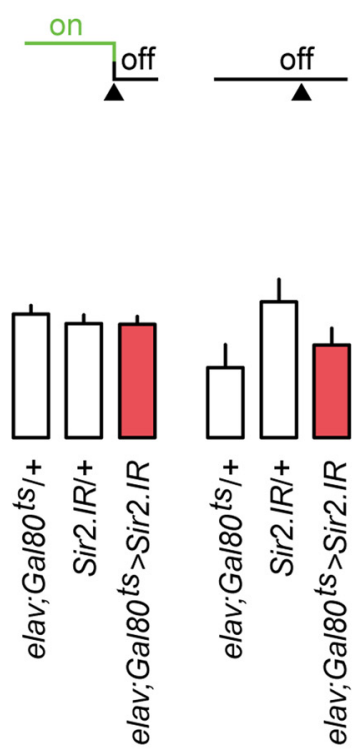

Figure 3. Sir2 activity is necessary in the adult brain for normal ethanol response behaviors. $\boldsymbol{A}, \boldsymbol{B}$, Sedation sensitivity $(\boldsymbol{A})$ and sedation tolerance $(\boldsymbol{B})$ in Sir2 ${ }^{-}$flies expressing wild-type Sir2 in the brain. Measurements are presented as the time to $25 \%$ sedation due to the marked increase in sedation resistance during exposure 2 in $\operatorname{Sir} 2^{-} ;$;elav $>\operatorname{Sir} 2(n=6-8)$. $\boldsymbol{C}, \boldsymbol{D}, \operatorname{Sedation}$ sensitivity $(\boldsymbol{C})$ and sedation tolerance $(\boldsymbol{D})$ in flies that have consumed the Sir2 inhibitor nicotinamide $(n=8) . \boldsymbol{E}$, $\boldsymbol{F}$, Sedation sensitivity $(\boldsymbol{E})$ and sedation tolerance $(\boldsymbol{F})$ in flies expressing Sir2 RNAi under temporal control, limited to adulthood $(n=18)$, development $(n=7-8)$, or inhibited through the entire lifespan $(n=6)$. Error bars indicate the SE. ${ }^{*} p<0.05$, ${ }^{* *} p<0.01$, triangle on temperature shift schematics indicates beginning of adult stage.

tinamide did not affect ethanol sedation sensitivity (unpaired $t$ test, $t_{(14)}=1.27, p=0.2251$; Fig. $3 C$ ) but strongly decreased ethanol sedation tolerance (unpaired $t$ test, $t_{(14)}=6.03, p<$ 0.0001 ; Fig. $3 D$ ). Second, we took advantage of a temperature sensitive GAL80 to limit Sir2.IR reduction of Sir2 expression levels to either development or adulthood. Ubiquitously expressed GAL $80^{\text {ts }}$ inhibits GAL4 activity at $19^{\circ} \mathrm{C}$ and allows GAL4 activity at $30^{\circ} \mathrm{C}$. When neuronal decreases in Sir2 were limited to adulthood, sedation sensitivity was decreased (one-way ANOVA, $F_{(2,51)}=23.57, p<0.0001$; Fig. $3 E$ ), and sedation tolerance was also decreased (one-way ANOVA, $F_{(2,51)}=10.23$, $p=0.0002$; Fig. $3 F$ ), recapitulating the $\operatorname{Sir} 2^{-}$behavioral phenotypes. When neuronal decreases in Sir2 were limited to development, no difference in behavior was observed (one-way ANOVA, $F_{(2,20)}=$ 0.46 , difference was not significant; Fig. $3 E, F$ ). Therefore, Sir2 activity is required in the adult nervous system for the development of ethanol tolerance.
Sir2 is required in the mushroom bodies for ethanol tolerance The mushroom bodies are a bilateral brain neuropil implicated in learning and memory, and also in ethanol preference and reward (Dubnau and Tully, 2001; Roman and Davis, 2001; Fiala, 2007; Busto et al., 2010; Kaun et al., 2011; Ojelade et al., 2015). In particular, the $\alpha / \beta$-lobes of the mushroom body are implicated in ethanol responses (Kaun et al., 2011; King et al., 2011; Ojelade et al., 2015). We investigated the role of the mushroom bodies in ethanol tolerance. To test whether mushroom body neurotransmission is important, we expressed the tetanus toxin light chain (TeTx) in the mushroom body $\alpha / \beta$-lobes using the $17 D-G A L 4$ driver line (Fig. 4A), preventing presynaptic vesicular release. While we observed variable effects for sedation sensitivity, there was a marked decrease in sedation tolerance (one-way ANOVA, $F_{(3,56)}=14.94, p<0.0001$; Fig. $\left.4 B, C\right)$. Addition of MB-GAL80, which prevents GAL4 activity specifically in the $\alpha / \beta$-lobes, attenuated, but did not completely ameliorate, the decreased tolerance 
A

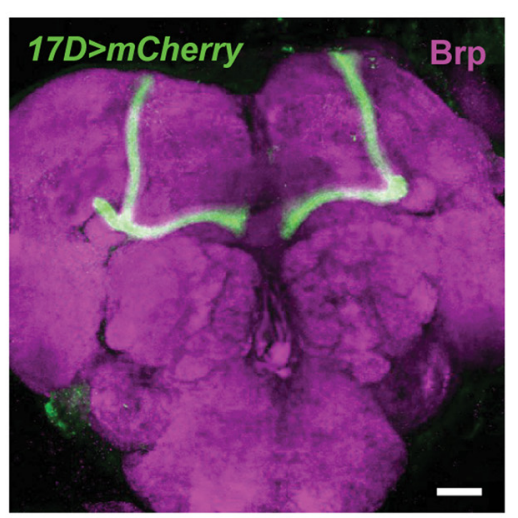

B
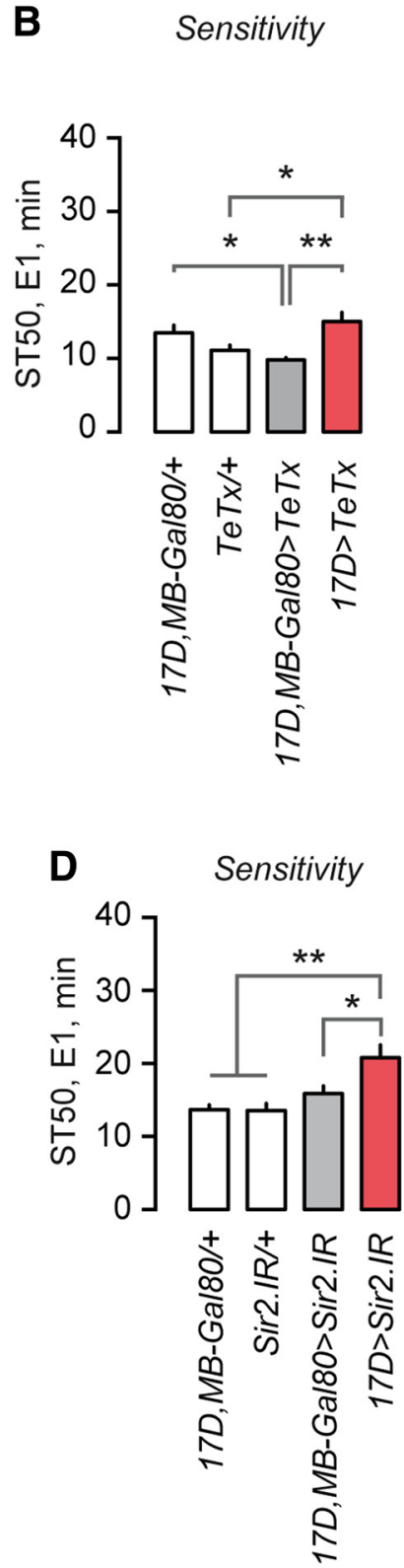

C

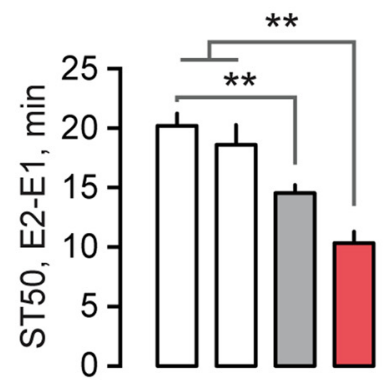

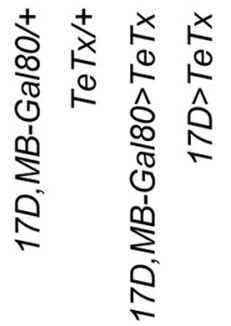

E

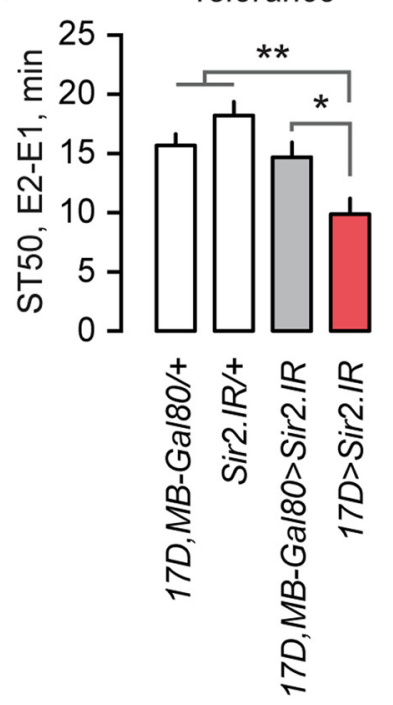

Figure 4. Sir2 acts in the mushroom body $\alpha / \beta$-neurons to promote ethanol tolerance. $A$, Compressed $z$-stack image of an adult brain immunostained for mCherry (driven in the $17 D$-GAL4 pattern, green) and the presynaptic protein Bruchpilot (Brp; magenta). $\boldsymbol{B}, \boldsymbol{C}$, Sedation sensitivity $(\boldsymbol{B})$ and sedation tolerance $(\boldsymbol{C})$ of flies expressing the tetanus toxin light chain (TeTx) in the $17 D$ pattern with or without MB-GAL80 to block mushroom body expression $(n=8)$. $\boldsymbol{D}, \boldsymbol{E}$, Sedation sensitivity $(\boldsymbol{D})$ and sedation tolerance $(\boldsymbol{E})$ of flies expressing Sir2 RNAi in the $17 D$ pattern in the mushroom bodies, with and without MB-GAL80 $(n=15)$. Error bars indicate the SE. ${ }^{*} p<0.05,{ }^{* *} p<0.01$.

phenotype (Tukey's test, $q=3.69, p=0.0653$; Fig. $4 C$ ). This experiment suggested that neuronal activity in the mushroom body $\alpha / \beta$-lobes promotes ethanol tolerance development.

We next asked whether Sir2 was required specifically in the mushroom body $\alpha / \beta$-lobe neurons. Mushroom body-specific Sir2.IR resulted in decreased sedation sensitivity (one-way ANOVA, $F_{(3,28)}=9.08, p<0.0001$; Fig. $\left.4 D\right)$ and decreased sedation tolerance (one-way ANOVA, $F_{(3,28)}=8.70, p<0.0001$; Fig. $4 E)$. This recapitulation of the Sir2 loss-of-function phenotypes was due to reduced Sir 2 expression in the $\alpha / \beta$-lobes: adding MBGAL80 blocked the Sir2.IR ethanol behavioral phenotypes (sensitivity: Tukey's test, $q=4.07, p=0.0283$; tolerance: Tukey's test, $q=4.37, p=0.0159$; Fig. $4 D, E)$. Thus, Sir2 is required in the mushroom bodies to promote ethanol sensitivity and the development of ethanol tolerance.
Sir2 is required for ethanol preference and reward

The mushroom bodies are required for ethanol preference and reward (Kaun et al., 2011; Xu et al., 2012; Ojelade et al., 2015). We asked whether the role of Sir2 may extend to these other forms of ethanol behavioral plasticity. Flies given a choice of liquid food with and without added ethanol will develop a preference for the ethanol food in the CAFE assay (Ja et al., 2007; Devineni and Heberlein, 2009). Flies that have developed ethanol preference will overcome adversity to gain the ethanol and show preference rebound following a period of abstinence. Additionally, flies preexposed to ethanol vapor develop ethanol preference much more rapidly (Peru y Colón de Portugal et al., 2014; Fig. 5A). Whereas ethanol pre-exposed control flies developed robust preference, Sir2 $2^{-}$flies did not (control: one sample $t$ test, $t_{(27)}=3.15, p=$ 0.004; Sir2 ${ }^{-}$: one sample $t$ test, $t_{(26)}=0.90$, difference was not 
A

Ethanol Preference
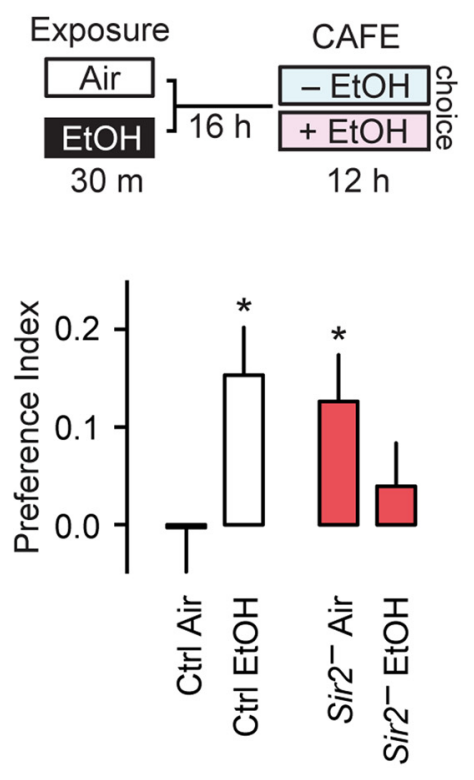

B

Bitter Taste Aversion

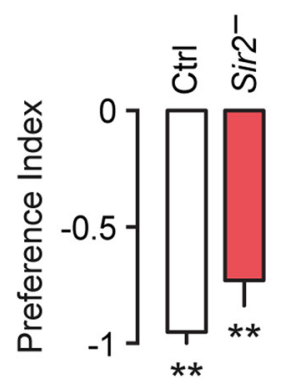

C
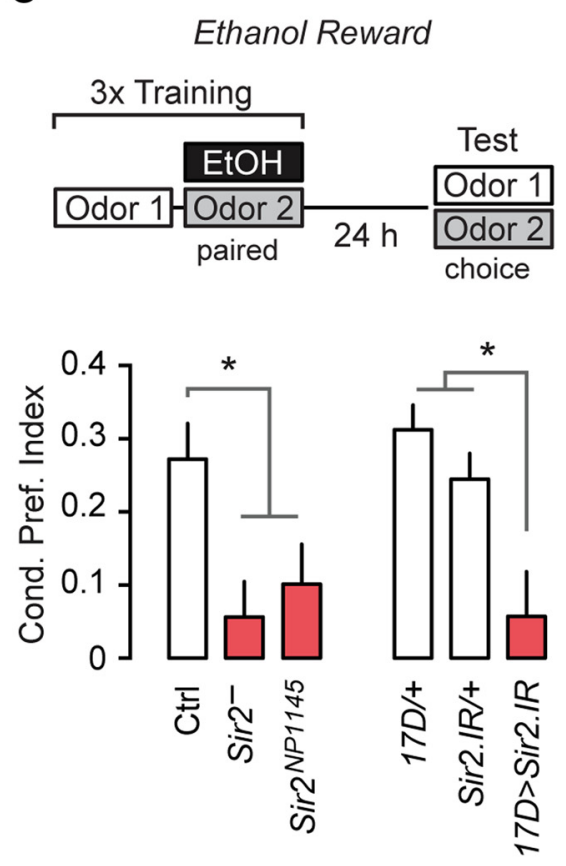

D

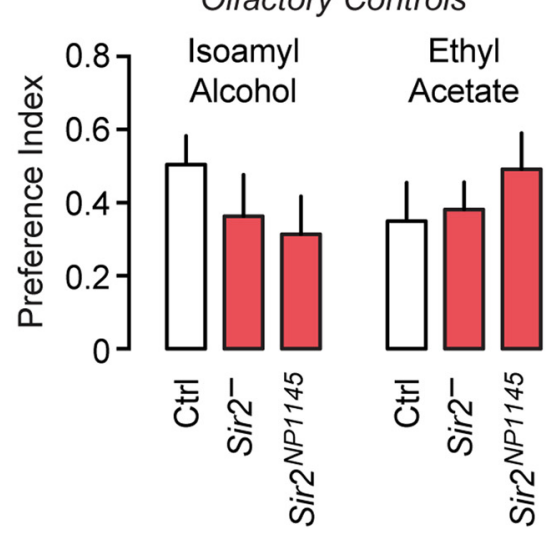

Ethanol reward in Drosophila is measured using a conditioned olfactory preference assay that is conceptually analogous to conditioned place preference in mammals (Kaun et al., 2011). The assay measures reward by pairing an odor with ethanol intoxication, and assessing paired versus unpaired odor attraction $24 \mathrm{~h}$ later. Sir 2 mutant flies showed strongly reduced conditioned odor preference, similar to their loss of ethanol-primed preference (one-way ANOVA, $F_{(2,43)}=5.67, p=$ 0.0065; Fig. $5 C$ ). This manifested as a loss of the rewarding effect of ethanol. Alternatively, a second aversive process may develop to mask reward in Sir ${ }^{-}$flies. Importantly, mushroom body-specific Sir2.IR also decreased conditioned odor preference (one-way ANOVA, $F_{(2,29)}=$ $9.19, p=0.0005$; Fig. $5 C$ ). Olfactory acuity for the pairing odors was unaffected in Sir2 mutants (one-way ANOVA; isoamyl alcohol: $F_{(2,21)}=0.99, p=0.3875$; ethyl acetate: $F_{(2,21)}=0.64, p=0.5387$; Fig. $5 D)$.

Together, these experiments demonstrate that Sir2 plays a more general role in mediating ethanol behavioral plasticity. However, whether this occurs through a common molecular target, shared behavior circuits, or a combination thereof is unknown. We hypothesize that the broad effects of Sir2 are suggestive of a shared molecular target known to affect behavioral plasticity in many different cell types.

\section{Sir2-dependent ethanol regulation of} presynaptic molecules: synapsin is required for tolerance

All known substrates for Sir2 deacetylase activity regulate gene transcription, including histone $\mathrm{H} 3$ acetylation. Ethanoldecreased expression of Sir2 may thus set in motion a transcriptional program that alters neuronal properties to change behavioral responses, such as those measured by assays for ethanol tolerance, preference, and reward. To identify genes that might contribute to Sir2-dependent

Figure 5. Sir2 is required for ethanol preference and for reward in the mushroom bodies. $A$, CAFE assay comparing the pre ence for liquid food with or without ethanol, with the schematic depicting the experimental design $(n=27-28)$. $\boldsymbol{B}$, Bitter taste aversion in flies given the choice of sucrose with and without quinine. A value of " -1 " indicates complete aversion $(n=7)$. $\boldsymbol{C}$ Conditioned olfactory preference to measure ethanol reward, with a schematic diagram of the experimental design in Sir2 mutants and flies expressing Sir2 RNAi under the control of the mushroom body driver 17D-GAL4 ( $n=14-16)$. D, Preference for the odorants isoamyl alcohol and ethyl acetate in the absence of pairing with ethanol inebriation $(n=8)$. Error bars indicate the SE. ${ }^{*} p<0.05,{ }^{* *} p<0.01$.

significant; Fig. 5A). In fact, Sir2 ${ }^{-}$flies preferred the ethanolcontaining food without an ethanol pre-exposure, suggesting that animals lacking Sir2 may be predisposed to drink ethanol (one-sample $t$ test, $t_{(27)}=2.65, p=0.0135$; Fig. $5 A$ ). This decreased preference in ethanol pre-exposed Sir $2^{-}$flies may be a loss of preference, or a developing aversion. Similarly, Sir2 ${ }^{-}$unconditioned ethanol preference could be due to a loss of avoidance of aversive stimuli. To test this, we gave flies a choice between $100 \mathrm{~mm}$ sucrose with bitter quinine and $50 \mathrm{~mm}$ sucrose. Sir2 mutants, like controls, showed a strong avoidance of the sweeter yet bitter quinine choice (control: one-sample $t$ test, $t_{(6)}=20, p<0.001 ;$ Sir2 $^{-}$: one-sample $t$ test, $t_{(6)}=6.708, p<$ 0.001 ; Fig. $5 B$ ). These findings imply that Sir 2 is more specifically involved in interpreting the value of ethanol intake. ethanol behaviors, we performed an RNAseq analysis of RNA isolated from the heads of Sir2 ${ }^{-}$and wild-type control flies that were treated with ethanol vapor or humidified air alone. We curated a list of 749 genes that showed large (twofold or higher) changes in expression with ethanol treatment in either genotype and that were expressed at detectable levels. Interestingly, there was remarkably little overlap in the genes that respond to ethanol in control and Sir2 ${ }^{-}$flies; of the 492 genes upregulated in wildtype flies in response to ethanol, only 52 were also upregulated in Sir2 $^{-}$flies treated with ethanol (Fig. 6A).

A marked change in Synapsin (Syn) RNA levels in Sir2 ${ }^{-}$suggested that Sir2 may regulate presynaptic function. Of genes encoding proteins predominantly localized to synapses, only $S y n$ expression was affected (decreased) in the heads of Sir2 mutants 
A

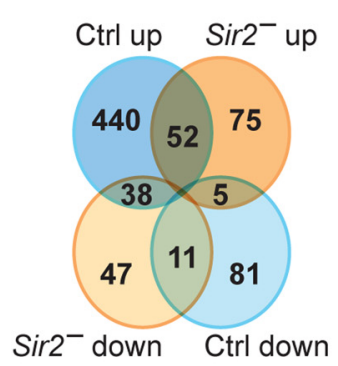

D

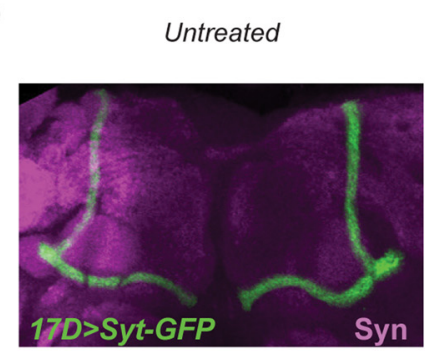

B

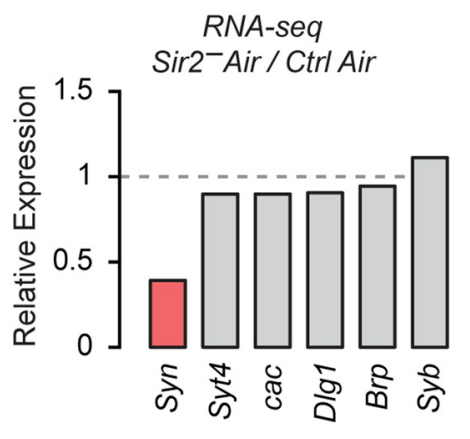

E

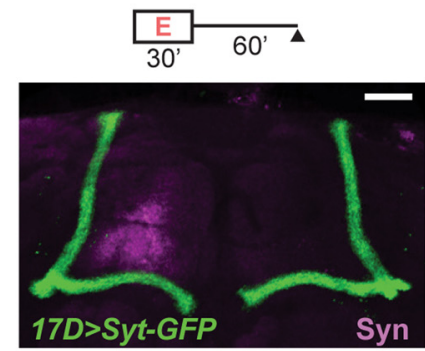

C

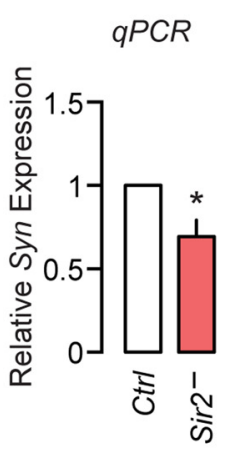

$\mathbf{F}$

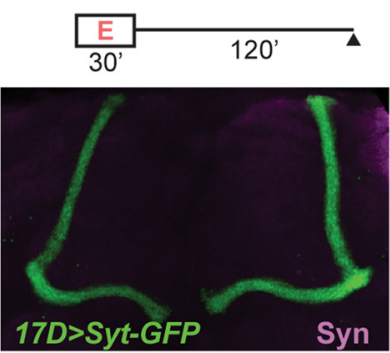

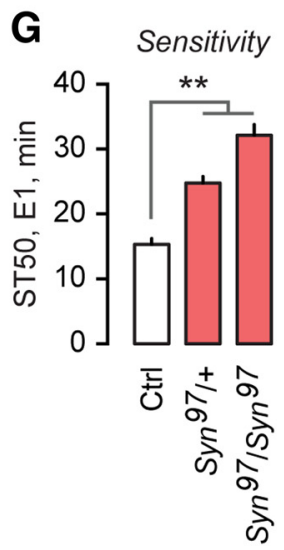
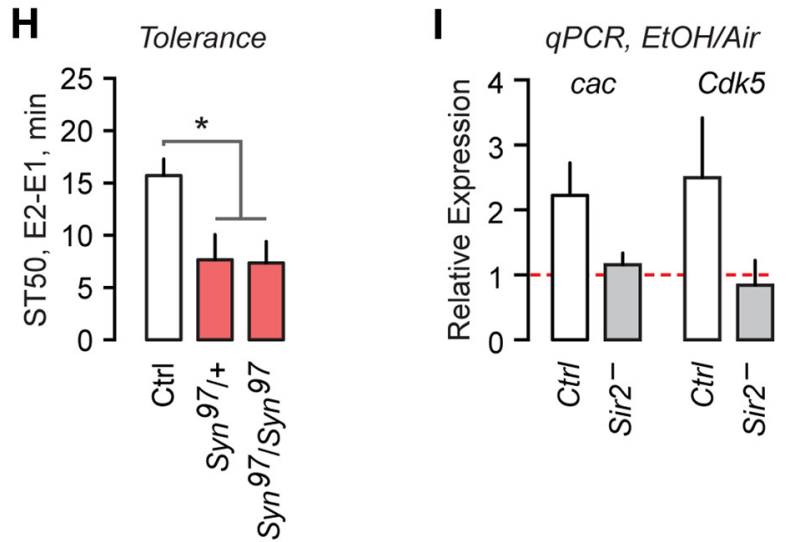

Figure 6. Presynaptic proteins are regulated by Sir2, and decreased Synapsin hinders ethanol tolerance. $A$, Diagram depicting genes upregulated and downregulated by ethanol exposure in control (blue) and Sir2 ${ }^{-}$(orange) flies, as assayed by RNAseq. B, Relative expression of genes coding for synaptic proteins between control and Sir2 ${ }^{-}$flies, assayed by RNA-seq. C, qPCR showing Syn expression changes in control and Sir2 ${ }^{-}$flies, with and without ethanol exposure (left, $n=9 ;$ right, $n=5-6$ ). $\boldsymbol{D}-\boldsymbol{F}$, Brains (25 $\mu \mathrm{m}$ projections) expressing synaptotagmin-GFP in 17d pattern (green) from untreated (D), 30 min ethanol plus 60 min recovery $(\boldsymbol{E})$, and 30 min ethanol plus 120 min recovery $(\boldsymbol{F})$ immunostained with Syn (magenta). Scale bar, $20 \mu \mathrm{m}$. $\mathbf{G}, \boldsymbol{H}$, Sedation sensitivity $(\boldsymbol{G})$ and sedation tolerance $(\boldsymbol{H})$ in Syn ${ }^{97}$ (Syn-null) flies vs controls $(n=8)$. $\boldsymbol{I}$, Relative mRNA expression of the presynaptic proteins Cac and Cdk5 in control and Sir2 ${ }^{-}$flies when assayed via qPCR in ethanol-treated vs untreated flies $(n=3)$. Error bars indicate the SE. ${ }^{*} p<0.05$, ${ }^{* *} p<0.01$.

(Fig. 6B). Syn encodes abundant presynaptic phosphoproteins that bind synaptic vesicles and regulate vesicle dynamics (Südhof, 2012). Syn is important in flies for learning and memory, usedependent synaptic growth, and the response to ethanol (Godenschwege et al., 2004; Vasin et al., 2014). Additionally, the chromatin state of the Syn promotor changes in response to sedation (Ghezzi et al., 2013). We verified Syn downregulation in Sir ${ }^{-}$flies by qPCR (one-sample $t$ test, $t_{(8)}=3.12, p=0.0142$; Fig. $6 C$, left). We then determined the effect of ethanol treatment on Syn RNA expression. In wild-type flies after recovery from ethanol exposure, Syn was significantly decreased compared with untreated controls (one-sample $t$ test, $t_{(4)}=3.49, p=0.0251$; Fig. $6 C$, right). Importantly, there was no such decrease in ethanolexposed Sir $2^{-}$flies compared with untreated Sir2 ${ }^{-}$(one-sample $t$ test, $t_{(5)}=0.57, p=0.5946$; Fig. $6 C$, right). To determine whether ethanol also decreases Syn protein expression, we immunostained control and ethanol-treated brains with a Syn antibody. Syn expression was strongly decreased throughout the brain by ethanol treatment (Fig. 6D-F). These data indicate that ethanol regulates Syn expression levels in a Sir2-dependent fashion.

We next investigated the role of Syn in behavior using a previously characterized null mutant of Syn in the ethanol sedation tolerance assay. Syn-null mutant flies $\left(\mathrm{Syn}^{97}\right)$ showed strongly decreased sedation sensitivity (one-way ANOVA, $F_{(2,21)}=46.47$, $p<0.0001$; Fig. $6 G$ ) and tolerance (one-way ANOVA, $F_{(2,21)}=$ 5.41, $p=0.013$; Fig. $6 H$ ), mimicking the phenotype of Sir $2^{-}$flies. Concordantly, a 50\% reduction of Syn expression in Syn-null heterozygotes was sufficient to decrease ethanol sensitivity and tolerance, suggesting that changes in presynaptic function may explain the role of Sir2 in ethanol behavioral responses. 
Expression of other presynaptic molecules may be regulated by ethanol in a Sir2-dependent manner. In wild-type and Sir2 ${ }^{-}$ fly heads treated with ethanol and allowed to recover, we assessed RNA transcript levels of the prominent presynaptic proteins cyclin-dependent kinase 5 (Cdk5), a cyclin-dependent kinase that influences presynaptic function, and Cacophony (Cac), the major presynaptic calcium channel. Like Syn, the cac genomic region shows changes in histone acetylation following sedation (Ghezzi et al., 2013). Both cac and Cdk5 RNA transcript levels increased, albeit not to statistical significance, in ethanol-treated wild-type flies compared with air-treated controls, but no increase was apparent in Sir2 ${ }^{-}$flies (Fig. 6I).

\section{Discussion}

Drugs of abuse engage epigenetic transcriptional programs that contribute to addiction-like behaviors (Wang et al., 2007; Renthal et al., 2009; Botia et al., 2012; Feng et al., 2014; Heller et al., 2014; Ferguson et al., 2015; Koo et al., 2015). We show that acute ethanol exposure, via the downregulation of Sir2, changes the expression of key presynaptic molecules and initiates behavioral adaptations in flies. Studies in mice demonstrate that SIRT1 is upregulated by long-term drug treatment. Further, experimentally increasing SIRT1 in the mouse nucleus accumbens enhances the rewarding effects of long-term cocaine and morphine administration, whereas reducing SIRT1 decreases it (Ferguson et al., 2013). The molecular mechanisms by which SIRT1 drives the reward for long-term drug exposure are partly understood. Our findings demonstrate that Sir2/SIRT1 functions across species for addictive drug action. More importantly, we tie the acute actions of ethanol to a transcriptional mechanism for effecting cellular and behavioral change. This pathway for early functional adaptations to ethanol may lay the molecular and circuit groundwork for the addictive liability of repeated drug intake. Further, it provides a molecular bridge between behavioral responses to ethanol, including sensitivity, tolerance, preference, and reward. A genetic relationship exists between ethanol tolerance and preference, but not sensitivity (Devineni et al., 2011). This is consistent with our findings that indicate separable roles for Sir2 in sensitivity and tolerance. However, Sir2 promotes the expression of Synapsin in ethanol-naive flies and permits its regulation in ethanol-treated flies. Therefore, Sir2 regulation of synaptic properties is likely a mechanism for the expression of both ethanol sensitivity and ethanol-induced behavioral plasticity. Sir2 works for sensitivity, tolerance, and reward in the Drosophila mushroom bodies, a central part of a circuit that appears to bear some functional equivalence to the vertebrate reward circuitry, tying these behaviors together anatomically, as well as molecularly.

How does Sir2 regulate behavioral plasticity? Ethanol, cocaine, opiates, and benzyl alcohol all lead to changes in covalent modifications in histones that likely affect gene transcription (Wang et al., 2007; Pandey et al., 2008; Renthal et al., 2009; Botia et al., 2012; Feng et al., 2014; Heller et al., 2014; Koo et al., 2015). However, only in rare cases are the enzymes that modify the histones or the functionally relevant target genes known for addictive drugs. Additionally, Sir2/SIRT1 deacetylates not only histones but also transcription factors that may impact ethanolinduced behavioral plasticity through changes in gene expression. For example, SIRT1 deacetylates the transcription factor FOXO3a, which is important for the development of conditioned place preference to chronic cocaine administration in mice (Ferguson et al., 2015). In flies, short-term exposure to ethanol and benzyl alcohol leads to changes in histone acetylation at many chromatin sites, including the region encoding the slowpoke BK- type $\mathrm{Ca}^{2+}$-activated $\mathrm{K}^{+}$channel that is involved in presynaptic function (Wang et al., 2007; Ghezzi et al., 2013). Both alcohols increase BK gene expression, and mutations in the channel decrease tolerance to the sedative effects of the drugs. The factors that regulate BK expression by ethanol and the causal link between BK gene regulation and the development of ethanol tolerance need further investigation. Of note, we were unable to detect ethanol- or Sir2-dependent changes in BK gene expression. However, our study used milder inebriation conditions and sampled gene expression earlier, so we cannot rule out a possible upstream role for Sir2 in BK channel regulation.

Our findings support a model whereby ethanol regulates the expression of presynaptic molecules through Sir2 activity. Whether ethanol inhibition of Sir2 increases H3K9 and possibly other histone residue acetylation to change chromatin accessibility, increases the acetylation of a transcription factor, or works through a more indirect mechanism will need to be determined. The unexpected promotion of H3K9 acetylation by Sir2 in ethanol-naive animals may also influence the pattern and extent of gene regulation by ethanol. However, our transcriptomic analysis detected remarkably little overlap of ethanol-regulated genes between wild-type control and Sir ${ }^{-}$heads, suggesting that Sir2 is broadly responsible for ethanol-dependent gene regulation.

Ethanol-induced changes in presynaptic properties may be a key way in which the drug alters the brain to change behavior (Lovinger and Roberto, 2013). Acute ethanol exposure increases presynaptic GABAergic release probability in the ventral tegmental area and the central amygdala of mice (Melis et al., 2002; Roberto et al., 2003). Acute ethanol exposure also affects the activity of presynaptic BK and calcium channels, generally decreasing their activity, and attenuating ethanol inebriation in mice (Newton et al., 2008; Li et al., 2014). Furthermore, the presynaptic vesicle-associated protein Munc13-1 binds ethanol, and flies lacking the gene show increased ethanol preference (Das et al., 2013). Finally, polymorphisms of syntaxin-interacting Munc18-1 correlate with mouse strains preferring ethanol, and mutation of the Caenorhabditis elegans ortholog reduces ethanol sensitivity (Graham et al., 2009). Chronic ethanol exposure also alters presynaptic function in mice (Lovinger and Roberto, 2013). Interestingly, chronic ethanol use increases presynaptic calcium channel function, suggesting molecular adaptation in the presynaptic compartment in the transition from acute to chronic exposure (Newton et al., 2005). Together, these findings suggest that ethanol impacts presynaptic function and causes presynaptic adaptation.

We show that Syn is regulated by ethanol in a Sir2-dependent manner, and suggest that $c a c$ and $C d k 5$ may also be regulated in the same manner. The direction of regulation-decreased Syn and increased cac and Cdk5-suggests that acute ethanol exposure may lead to presynaptic adaptations that increase neurotransmitter release. Syn binds to synaptic vesicles and to actin, and it is proposed to maintain the reserve pool of synaptic vesicles (Bykhovskaia, 2011). Mutational disruption and ethanolinduced decreased levels of Syn may lead to greater dynamics of the reserve pool that manifest phenotypically with strong stimulation or in behavioral measurements of plasticity (Sun et al., 2006; Niewalda et al., 2015). Studies at the fly neuromuscular junction suggest that normal physiological synaptic homeostasis is essentially intact in Syn mutants, whereas the addition of new synaptic boutons due to strong stimulation is lost (Vasin et al., 2014). Further, Syn mutant flies are remarkably normal for spontaneous behavior, but show moderate to strong defects in various forms of learning and memory (Godenschwege et al., 2004; Mi- 
chels et al., 2005; Knapek et al., 2010; Sadanandappa et al., 2013). Both Syn and Cac are phosphorylated by Cdk 5 to regulate aspects of presynaptic function (Su et al., 2012; Verstegen et al., 2014). Acute ethanol exposure may increase Cdk5 to promote phosphorylation of a smaller pool of Syn, leading to greater vesicle dynamics in response to synaptic stimulation, and also may facilitate neurotransmitter release by phosphorylation of Cac. Behavioral plasticity initiated by acute ethanol exposure may be molecularly tied to changes in synaptic function or connectivity evoked by strong stimuli. Alternatively, Sir2 may allow a compensatory return of presynaptic molecules to prestimulus levels, a process required for the expression of behavioral plasticity.

The mushroom body intrinsic Kenyon cells of the $\alpha / \beta$-lobe, where Sir2 is required for ethanol tolerance and reward, are important for both appetitive and aversive memory, and also for alcohol reward (Kaun et al., 2011; Aso et al., 2014). These Kenyon cells are connected synaptically to diverse input and output neurons, and they integrate sensory and internal-state inputs to drive innate and learned responses. Our findings imply that Sir2dependent transcriptional regulation in the mushroom bodies is important for aspects of information processing that lead to the fly altering its behavioral responses to ethanol.

Our findings tie the gene regulatory effects of acute ethanol use to ethanol-induced behavioral plasticity in a brain region that associates context with innate approach-and-avoidance responses. How these ethanol-induced molecular changes impact neuronal function, and also interface with other molecular and cellular effects of acute ethanol exposure will help to define how circuits change to reinforce drug intake (Beckley et al., 2016). The mechanisms for ethanol-induced plasticity may be partly shared with those influencing natural and other pharmacologically induced neural plasticity, and it will be important to decipher how they integrate into the neural circuitry for addiction.

\section{References}

Aso Y, Sitaraman D, Ichinose T, Kaun KR, Vogt K, Belliart-Guérin G, Plaçais PY, Robie AA, Yamagata N, Schnaitmann C, Rowell WJ, Johnston RM, Ngo TT, Chen N, Korff W, Nitabach MN, Heberlein U, Preat T, Branson KM, Tanimoto H, et al. (2014) Mushroom body output neurons encode valence and guide memory-based action selection in Drosophila. eLife 3:e04580. CrossRef Medline

Beckley JT, Laguesse S, Phamluong K, Morisot N, Wegner SA, Ron D (2016) The first alcohol drink triggers mTORC1-dependent synaptic plasticity in nucleus accumbens dopamine D1 receptor neurons. J Neurosci 36:701713. CrossRef Medline

Blankenberg D, Kuster GV, Coraor N, Ananda G, Lazarus R, Mangan M, Nekrutenko A, Taylor J (2010) Galaxy: a web-based genome analysis tool for experimentalists. Curr Protoc Mol Biol 89:UNIT 19.10.

Botia B, Legastelois R, Alaux-Cantin S, Naassila M (2012) Expression of ethanol-induced behavioral sensitization is associated with alteration of chromatin remodeling in mice. PLoS One 7:e47527. CrossRef Medline

Busto GU, Cervantes-Sandoval I, Davis RL (2010) Olfactory learning in Drosophila. Physiology 25:338-346. CrossRef Medline

Bykhovskaia M (2011) Synapsin regulation of vesicle organization and functional pools. Semin Cell Dev Biol 22:387-392. CrossRef Medline

Das C, Lucia MS, Hansen KC, Tyler JK (2009) CBP/p300-mediated acetylation of histone $\mathrm{H} 3$ on lysine 56. Nature 459:113-117. CrossRef Medline

Das J, Xu S, Pany S, Guillory A, Shah V, Roman GW (2013) The pre-synaptic Munc13-1 binds alcohol and modulates alcohol self-administration in Drosophila. J Neurochem 126:715-726. CrossRef Medline

Devineni AV, Heberlein U (2009) Preferential ethanol consumption in Drosophila models features of addiction. Curr Biol 19:2126-2132. CrossRef Medline

Devineni AV, McClure KD, Guarnieri DJ, Corl AB, Wolf FW, Eddison M, Heberlein U (2011) The genetic relationships between ethanol preference, acute ethanol sensitivity and ethanol tolerance in Drosophila melanogaster. Fly (Austin) 5:191-199. CrossRef Medline
Dubnau J, Tully T (2001) Functional anatomy: from molecule to memory. Curr Biol 11:R240-R243. CrossRef Medline

Dudley R (2000) Evolutionary origins of human alcoholism in primate frugivory. Q Rev Biol 75:3-15. CrossRef Medline

Feng J, Wilkinson M, Liu X, Purushothaman I, Ferguson D, Vialou V, Maze I, Shao N, Kennedy P, Koo J, Dias C, Laitman B, Stockman V, LaPlant Q, Cahill ME, Nestler EJ, Shen L (2014) Chronic cocaine-regulated epigenomic changes in mouse nucleus accumbens. Genome Biol 15:R65. CrossRef Medline

Ferguson D, Koo JW, Feng J, Heller E, Rabkin J, Heshmati M, Renthal W, Neve R, Liu X, Shao N, Sartorelli V, Shen L, Nestler EJ (2013) Essential role of SIRT1 signaling in the nucleus accumbens in cocaine and morphine action. J Neurosci 33:16088-16098. CrossRef Medline

Ferguson D, Shao N, Heller E, Feng J, Neve R, Kim HD, Call T, Magazu S, Shen L, Nestler EJ (2015) SIRT1-FOXO3a regulate cocaine actions in the nucleus accumbens. J Neurosci 35:3100-3111. CrossRef Medline

Fiala A (2007) Olfaction and olfactory learning in Drosophila: recent progress. Curr Opin Neurobiol 17:720-726. CrossRef Medline

Finegersh A, Homanics GE (2014) Acute ethanol alters multiple histone modifications at model gene promoters in the cerebral cortex. Alcohol Clin Exp Res 38:1865-1873. CrossRef Medline

Ghezzi A, Krishnan HR, Lew L, Prado FJ 3rd, Ong DS, Atkinson NS (2013) Alcohol-induced histone acetylation reveals a gene network involved in alcohol tolerance. PLoS Genet 9:e1003986. CrossRef Medline

Ghezzi A, Krishnan HR, Atkinson NS (2014) Susceptibility to ethanol withdrawal seizures is produced by BK channel gene expression. Addict Biol 19:332-337. CrossRef Medline

Giardine B, Riemer C, Hardison RC, Burhans R, Elnitski L, Shah P, Zhang Y, Blankenberg D, Albert I, Taylor J, Miller W, Kent WJ, Nekrutenko A (2005) Galaxy: a platform for interactive large-scale genome analysis. Genome Res 15:1451-1455. CrossRef Medline

Godenschwege TA, Reisch D, Diegelmann S, Eberle K, Funk N, Heisenberg M, Hoppe V, Hoppe J, Klagges BR, Martin JR, Nikitina EA, Putz G, Reifegerste R, Reisch N, Rister J, Schaupp M, Scholz H, Schwärzel M, Werner U, Zars TD, et al. (2004) Flies lacking all synapsins are unexpectedly healthy but are impaired in complex behaviour. Eur J Neurosci 20: 611-622. CrossRef Medline

Goecks J, Nekrutenko A, Taylor J (2010) Galaxy: a comprehensive approach for supporting accessible, reproducible, and transparent computational research in the life sciences. Genome Biol 11:R86. CrossRef Medline

Graham ME, Edwards MR, Holden-Dye L, Morgan A, Burgoyne RD, Barclay JW (2009) UNC-18 modulates ethanol sensitivity in Caenorhabditis elegans. Mol Biol Cell 20:43-55. CrossRef Medline

Heller EA, Cates HM, Peña CJ, Sun H, Shao N, Feng J, Golden SA, Herman JP, Walsh JJ, Mazei-Robison M, Ferguson D, Knight S, Gerber MA, Nievera C, Han MH, Russo SJ, Tamminga CS, Neve RL, Shen L, Zhang HS, et al. (2014) Locus-specific epigenetic remodeling controls addiction- and depression-related behaviors. Nat Neurosci 17:1720-1727. CrossRef Medline

Henry GL, Davis FP, Picard S, Eddy SR (2012) Cell type-specific genomics of Drosophila neurons. Nucleic Acids Res 40:9691-9704. CrossRef Medline

Ja WW, Carvalho GB, Mak EM, de la Rosa NN, Fang AY, Liong JC, Brummel T, Benzer S (2007) Prandiology of Drosophila and the CAFE assay. Proc Natl Acad Sci U S A 104:8253-8256. CrossRef Medline

Kacsoh BZ, Lynch ZR, Mortimer NT, Schlenke TA (2013) Fruit flies medicate offspring after seeing parasites. Science 339:947-950. CrossRef Medline

Kaun KR, Azanchi R, Maung Z, Hirsh J, Heberlein U (2011) A Drosophila model for alcohol reward. Nat Neurosci 14:612-619. CrossRef Medline

Kerns RT, Ravindranathan A, Hassan S, Cage MP, York T, Sikela JM, Williams RW, Miles MF (2005) Ethanol-responsive brain region expression networks: implications for behavioral responses to acute ethanol in DBA/2J versus C57BL/6J mice. J Neurosci 25:2255-2266. CrossRef Medline

King I, Tsai LT, Pflanz R, Voigt A, Lee S, Jäckle H, Lu B, Heberlein U (2011) Drosophila tao controls mushroom body development and ethanolstimulated behavior through par-1. J Neurosci 31:1139-1148. CrossRef Medline

Knapek S, Gerber B, Tanimoto H (2010) Synapsin is selectively required for anesthesia-sensitive memory. Learn Mem 17:76-79. CrossRef Medline

Kong EC, Allouche L, Chapot PA, Vranizan K, Moore MS, Heberlein U, Wolf 
FW (2010) Ethanol-regulated genes that contribute to ethanol sensitivity and rapid tolerance in Drosophila. Alcohol Clin Exp Res 34:302-316. CrossRef Medline

Koo JW, Mazei-Robison MS, LaPlant Q, Egervari G, Braunscheidel KM, Adank DN, Ferguson D, Feng J, Sun H, Scobie KN, Damez-Werno DM, Ribeiro E, Peña CJ, Walker D, Bagot RC, Cahill ME, Anderson SA, Labonté B, Hodes GE, Browne H, et al. (2015) Epigenetic basis of opiate suppression of Bdnf gene expression in the ventral tegmental area. Nat Neurosci 18:415-422. CrossRef Medline

Krashes MJ, Keene AC, Leung B, Armstrong JD, Waddell S (2007) Sequential use of mushroom body neuron subsets during Drosophila odor memory processing. Neuron 53:103-115. CrossRef Medline

Li Q, Madison R, Moore SD (2014) Presynaptic BK channels modulate ethanol-induced enhancement of GABAergic transmission in the rat central amygdala nucleus. J Neurosci 34:13714-13724. CrossRef Medline

Lovinger DM, Roberto M (2013) Synaptic effects induced by alcohol. Curr Top Behav Neurosci 13:31-86. CrossRef Medline

Mahadev K, Vemuri MC (1998) Effect of ethanol on chromatin and nonhistone nuclear proteins in rat brain. Neurochem Res 23:1179-1184. CrossRef Medline

Maze I, Nestler EJ (2011) The epigenetic landscape of addiction. Ann N Y Acad Sci 1216:99-113. CrossRef Medline

Melis M, Camarini R, Ungless MA, Bonci A (2002) Long-lasting potentiation of GABAergic synapses in dopamine neurons after a single in vivo ethanol exposure. J Neurosci 22:2074-2082. Medline

Michels B, Diegelmann S, Tanimoto H, Schwenkert I, Buchner E, Gerber B (2005) A role for Synapsin in associative learning: the Drosophila larva as a study case. Learn Mem 12:224-231. CrossRef Medline

Moore MS, DeZazzo J, Luk AY, Tully T, Singh CM, Heberlein U (1998) Ethanol intoxication in Drosophila: genetic and pharmacological evidence for regulation by the cAMP signaling pathway. Cell 93:997-1007. CrossRef Medline

Morozova TV, Anholt RR, Mackay TF (2006) Transcriptional response to alcohol exposure in Drosophila melanogaster. Genome Biol 7:R95. CrossRef Medline

Mruk DD, Cheng CY (2011) Enhanced chemiluminescence (ECL) for routine immunoblotting. Spermatogenesis 1:121-122. CrossRef Medline

Newton PM, Tully K, McMahon T, Connolly J, Dadgar J, Treistman SN, Messing RO (2005) Chronic ethanol exposure induces an N-type calcium channel splice variant with altered channel kinetics. FEBS Lett 579: 671-676. CrossRef Medline

Newton PM, Zeng L, Wang V, Connolly J, Wallace MJ, Kim C, Shin HS, Belardetti F, Snutch TP, Messing RO (2008) A blocker of N- and T-type voltage-gated calcium channels attenuates ethanol-induced intoxication, place preference, self-administration, and reinstatement. J Neurosci 28: 11712-11719. CrossRef Medline

Niewalda T, Michels B, Jungnickel R, Diegelmann S, Kleber J, Kähne T, Gerber B (2015) Synapsin determines memory strength after punishmentand relief-learning. J Neurosci 35:7487-7502. CrossRef Medline

Ojelade SA, Jia T, Rodan AR, Chenyang T, Kadrmas JL, Cattrell A, Ruggeri B, Charoen P, Lemaitre H, Banaschewski T, Büchel C, Bokde AL, Carvalho F, Conrod PJ, Flor H, Frouin V, Gallinat J, Garavan H, Gowland PA, Heinz A, et al. (2015) Rsul regulates ethanol consumption in Drosophila and humans. Proc Natl Acad Sci U S A 112:E4085-E4093. CrossRef Medline

Pandey SC, Ugale R, Zhang H, Tang L, Prakash A (2008) Brain chromatin remodeling: a novel mechanism of alcoholism. J Neurosci 28:3729-3737. CrossRef Medline

Peru y Colón de Portugal RL, Ojelade SA, Penninti PS, Dove RJ, Nye MJ, Acevedo SF, Lopez A, Rodan AR, Rothenfluh A (2014) Long-lasting, experience-dependent alcohol preference in Drosophila. Addict Biol 19: 392-401. CrossRef Medline

Renthal W, Kumar A, Xiao G, Wilkinson M, Covington HE 3rd, Maze I,
Sikder D, Robison AJ, LaPlant Q, Dietz DM, Russo SJ, Vialou V, Chakravarty S, Kodadek TJ, Stack A, Kabbaj M, Nestler EJ (2009) Genomewide analysis of chromatin regulation by cocaine reveals a role for sirtuins. Neuron 62:335-348. CrossRef Medline

Roberto M, Madamba SG, Moore SD, Tallent MK, Siggins GR (2003) Ethanol increases GABAergic transmission at both pre- and postsynaptic sites in rat central amygdala neurons. Proc Natl Acad Sci U S A 100:20532058. CrossRef Medline

Roman G, Davis RL (2001) Molecular biology and anatomy of Drosophila olfactory associative learning. Bioessays 23:571-581. CrossRef Medline

Sadanandappa MK, Blanco Redondo B, Michels B, Rodrigues V, Gerber B, VijayRaghavan K, Buchner E, Ramaswami M (2013) Synapsin function in GABAergic interneurons is required for short-term olfactory habituation. J Neurosci 33:16576-16585. CrossRef Medline

Sakharkar AJ, Zhang H, Tang L, Shi G, Pandey SC (2012) Histone deacetylases (HDAC)-induced histone modifications in the amygdala: a role in rapid tolerance to the anxiolytic effects of ethanol. Alcohol Clin Exp Res 36:61-71. CrossRef Medline

Scholz H, Ramond J, Singh CM, Heberlein U (2000) Functional ethanol tolerance in Drosophila. Neuron 28:261-271. CrossRef Medline

Shohat-Ophir G, Kaun KR, Azanchi R, Mohammed H, Heberlein U (2012) Sexual deprivation increases ethanol intake in Drosophila. Science 335: 1351-1355. CrossRef Medline

Su SC, Seo J, Pan JQ, Samuels BA, Rudenko A, Ericsson M, Neve RL, Yue DT, Tsai LH (2012) Regulation of N-type voltage-gated calcium channels and presynaptic function by cyclin-dependent kinase 5 . Neuron 75 : 675-687. CrossRef Medline

Südhof TC (2012) The presynaptic active zone. Neuron 75:11-25. CrossRef Medline

Sun J, Bronk P, Liu X, Han W, Südhof TC (2006) Synapsins regulate usedependent synaptic plasticity in the calyx of Held by a Ca2+/calmodulindependent pathway. Proc Natl Acad Sci U S A 103:2880-2885. CrossRef Medline

Trapnell C, Roberts A, Goff L, Pertea G, Kim D, Kelley DR, Pimentel H, Salzberg SL, Rinn JL, Pachter L (2012) Differential gene and transcript expression analysis of RNA-seq experiments with TopHat and Cufflinks. Nat Protoc 7:562-578. CrossRef Medline

Urizar NL, Yang Z, Edenberg HJ, Davis RL (2007) Drosophila homer is required in a small set of neurons including the ellipsoid body for normal ethanol sensitivity and tolerance. J Neurosci 27:4541-4551. CrossRef Medline

Vasin A, Zueva L, Torrez C, Volfson D, Littleton JT, Bykhovskaia M (2014) Synapsin regulates activity-dependent outgrowth of synaptic boutons at the Drosophila neuromuscular junction. J Neurosci 34:10554-10563. CrossRef Medline

Verstegen AM, Tagliatti E, Lignani G, Marte A, Stolero T, Atias M, Corradi A, Valtorta F, Gitler D, Onofri F, Fassio A, Benfenati F (2014) Phosphorylation of synapsin I by cyclin-dependent kinase- 5 sets the ratio between the resting and recycling pools of synaptic vesicles at hippocampal synapses. J Neurosci 34:7266-7280. CrossRef Medline

Wang Y, Krishnan HR, Ghezzi A, Yin JC, Atkinson NS (2007) Druginduced epigenetic changes produce drug tolerance. PLoS Biol 5:e265. CrossRef Medline

Wolf FW, Rodan AR, Tsai LT, Heberlein U (2002) High-resolution analysis of ethanol-induced locomotor stimulation in Drosophila. J Neurosci 22: 11035-11044. Medline

Wu JS, Luo L (2006) A protocol for dissecting Drosophila melanogaster brains for live imaging or immunostaining. Nat Protoc 1:2110-2115. CrossRef Medline

Xu S, Chan T, Shah V, Zhang S, Pletcher SD, Roman G (2012) The propensity for consuming ethanol in Drosophila requires rutabaga adenylyl cyclase expression within mushroom body neurons. Genes Brain Behav 11:727-739. CrossRef Medline 